\title{
Buzzer and Word-of-Mouth in Online Transaction
}

\author{
$1^{\text {st* }}$ Salma Nadiya Putri \\ Communication Science \\ Universitas Indonesia \\ Jakarta, Indonesia \\ salmanadiyaputri@gmail.com
}

\author{
$2^{\text {nd }}$ Fitria Angeliqa \\ Communication Science \\ Universitas Indonesia \\ Jakarta, Indonesia \\ ivyangeliaca@yahoo.com
}

\begin{abstract}
Technological developments that make changes to all aspects of human life, we can access any and all information easily and quickly. included in buying and selling activities which can now be done anytime and anywhere. But then this becomes an obstacle when people want to make sure the goods, because of the limitations cannot see the condition of the goods directly. Then word-of-mouth is a solution to these limitations, because reviews from someone who is experienced and buying these items will be more trusted by other prospective customers compared to the advertisements of these products. word of mouth is usually in the comments page of the product page or it can be a blog containing a review of a product. In addition to word of mouth, buzzer also plays an important role in expanding the network of a product. Buzzer will post a product so that the share of voice of a product on the internet increases and causes the product to become more famous and increase consumer confidence. Sociolla is one of the e-commerce beauties that uses word of mouth and buzzer on the internet.
\end{abstract}

Keywords- Digital age, Communication, Word-of-Mouth, Buzzer, Blog

\section{INTRODUCTION}

The development of technology from time to time has created major changes in the world of information and communications. In ancient times, humans interacted with symbols such as artifacts and paintings, then language and letters were created to communicate verbally. This way of communication makes it easy for humans to communicate with each other quickly and easily, but has the disadvantage of messages not being able to be sent over long distances. Finally, in 1798, a communication revolution birthed the postal system also known as the delivery of letters. This was supported by the progressive transportation and infrastructure systems in the West. The beginning of the communication revolution originated from the invention of the printing press by Gutenberg [1] The revolution in communication takes the form of structural transformation which is a series of media revolutions creating wide and large changes, which affect economic, political and cultural aspects in Europe. Then later, in the course of globalization, everyone in the world becomes connected thanks to the wide arrangement of technological advancements. The communication revolution has now entered the era of digitization, where everyone in this world now utilizes digital media in their everyday communications. Digital media is a device in the form of electronic media that stores data in digital form. Technological advances play a major role in the development of digital media. Modern humans use digital devices such as cellphones and laptops as a means of activity and entertainment. This is because digital media is very practical and not old-fashioned unlike analog media.
In the digital age, people are connected through the internet and no longer rely on face-to-face communication. This also applies to business activities which include the buying and selling of products. Right now, consumers find it very easy that they are able to buy an item without visiting the store physically. They only need a cellphone or a laptop that is connected to the internet to visit the seller's website and then click the buy button and their goods will arrive within a certain time. But this then becomes a problem because buyers cannot see the goods directly and only rely on photos or comments from previous consumers. These consumer comments can be a benchmark of trust for other potential customers. The more positive comments given by previous consumers, the bigger the confidence of prospective consumers in regard to the product.

\section{Word-of-Mouth}

Information shared through word-of-mouth has largely been studied as a source of information for tourists, not from the perspective of a communicator on holiday experiences. Several studies have investigated segments based on the use of different sources of information in the context of vacation planning and decision making, these studies identify segments with varying degrees of importance by word-of-mouth and other sources of information. However, all of these studies see word-of-mouth as a homogeneous activity consider heterogeneity to some extent by distinguishing between different sources of word-of-mouth (friends and relatives vs. other tourists), but do not investigate differences in approaches used by communicators.

To this day, only a few studies have investigated word-ofmouth behavior from the communicator's perspective. In a study of trust from various online information sources, [2] reported descriptive results regarding the desire to share digital content after returning from vacation. Munar and Jacobsen found that tourists showed different levels of desire to use certain types of media (Facebook, blogs, Twitter, online reviews, email / sms / mms) in sharing their content. Sending emails and texts / multimedia messages are reported to be the most popular. While Munar and Jacobsen pointed out that the popularity of various digital communication channels varies, they did not investigate the combination of media used or the type of content shared. The findings of Bronner and de Hoog [3] show that motivation to post influences the type of website on which online reviews are conducted, the number of aspects handled, the valence of the review, and, to a lesser extent, whether or not images are used. While Bronner and de Hoog identified sources for differences in several aspects of content, they only investigated one electronic activity by word-ofmouth (posting online reviews). Lo investigated different single electronic word-of-mouth activities (sharing photos 
online) and identified different segments of dividers based on the type of media used. These studies provide valuable insights on how word-of-mouth creators can differ, but there is no research that addresses heterogeneity in word-of-mouth activity that results from a combination of traditional and electronic word-of-mouth as well as a mixture of visual and verbal content [4]

The value of word-of-mouth arises as a result of its impact on actual and potential buyers. Positive comments from satisfied customers can increase potential customers and eventually purchases, while negative comments from dissatisfied customers can reduce purchases from these potential customers. [5] found personal influence seven times more effective than magazine or newspaper advertisements, in persuading housewives to switch their brands of household products. Similarly, [6] found interpersonal sources to be the most effective in persuading housewives to try new fabrics. Roselius [7] found that word-of-mouth evokes a neutral or slightly favorable response in releasing all types of risk regardless of physical risk. More and more consumers are resisting the risk of finding word-of-mouth a very useful strategy in reducing most types of risk, and certain consumers are found to rate word-of-mouth very highly. Consideration of consumer motives for engaging in word-of-mouth tends to highlight the importance of customer satisfaction and related results as determinants of positive word-of-mouth.

The potential impact of word-of-mouth (WOM) and its value for the organization is huge, although as an informal channel, opportunities for organizations to manage WOM may be more difficult to identify. Of course, most research done in connection with WOM communication tends to focus on consumers as WOM users or consumers as WOM providers. Consideration of consumer motives for engaging in WOM tends to highlight the importance of customer satisfaction and related results as positive determinants of WOM. There is extensive evidence of the relationship between satisfaction and the desire to recommend [8]. In the same way, there are arguments associating dissatisfaction with negative WOM. Surely, dissatisfaction has been widely identified as an antecedent of complaining behavior, but only in cases where consumers feel unwilling or unable to complain. Customer loyalty also plays an important role as an antecedent in WOM communication. [9] argue that loyal customers are a prerequisite for positive WOM. This relationship is also supported by [10] who cite a study by General Electric with the finding that recommendations from friends and acquaintances have a double effect on paid advertising when consumers make purchasing decisions. In addition, Gremler and Brown propose that customers who provide positive WOM to other consumers, about service providers, are more likely to be loyal customers, thus implying that word-of-mouth might have benefits in terms of retention and acquisition.

\section{Communication in the Digital Era}

Digital media is a device in the form of electronic media that stores data in digital form. Technological advances play a major role in the development of digital media. Modern humans use digital devices such as cellphones and laptops as a means of activity and entertainment. The Digital Media Alliance Florida (DMAF) defines digital media as the creative convergence of digital art, science, technology and business for human expression, communication, social interaction and education. The convenience provided by digital media is an attraction for the public, as digital media is very practical and not old-fashioned unlike analog media. Technology in digital media uses satellites and optical fiber transmission as a means to distribute information. Modems can be used as converters of digital information on the computer, to analog signals that are used for telephone lines and to convert analog telephone signals to digital information for computers.

Digital technology has become ubiquitous and inevitable. Every day fewer non-digits are left as more people are becoming digital immigrants, and eventually are replaced by digital natives. Billions of devices are now connected, because remote access and added value of IoT have become commonplace. The Cloud Service has replaced previous digital products, personal data has become more valuable than most other resources. Now it's almost impossible for anyone to exist outside of Digital; it is almost impossible not to rely on online services, not to collect data, to not have information specifically designed for personal consumption based on unique digital footprints. The UX Design paradigm has shifted, keeping us away from simple interactions, deviating from the on-screen interface, and simultaneously eliminating the need for user encyclopedic competencies (eco-friendly) and even beyond national competency (according to Bankov). The communication structure determines the results of communication. The structure of communication literally shapes our world, as Benedict Anderson said. While his analysis turned to printing as a causal mechanism for the formation of the nation-state, one could argue that the al-based information delivery structure means release from the potential for accidental discovery and changing our system of hope, the way we think, and the way we see the world. If the whole system is based on our past, a mirror of ourselves, this means that we are more likely to accept answers relating to the world that is entirely within our scope. The further we depart from encyclopaedia competence, and eventually from navigation competence (where we can at least browse to unknown areas), the further we move from foreign ones. There exist event horizons, outside information that is completely beyond our reach, and these event horizons are getting closer to us [11]

As a low-cost communication resource, "Internet and Web capabilities have become a boon for social media activists". Supporters can join a movement without leaving their computers, simply by sharing negative information about the target organization, and thus undermining the organization's legitimacy and tarnishing its reputation. While the ease of retweeting or liking activist messages has led some to call the term online activism, "slacktivism" when organized, even "slacktivists" can cause damage to an organization's reputation [12]. The internet has fundamentally changed the modern media environment and media consumption habits of the audience. The volume of content about science and technology in traditional news outlets has subsided due to a significant decline in the number of readers and subscriptions. In turn, this decline has forced media companies to reduce the number of journalists who specialize in communicating scientific issues. In 1989, there were 95 weekly science sections in newspapers in the United States. However, in 2005 , less than one third of this remained, and that number dropped to 19 in 2012. Given these changes, the boundaries of 
communication that exist between scientists, journalists, and public hearings have become more blurred. The public relies on a variety of media, both on traditional and online platforms, for science news and information. Almost half of the public turns to online sources to keep abreast of developments in the scientific field. This presents new opportunities for scientists to play an active role in directly communicating with different segments of the public.

\section{Buzzer}

The buzzer phenomenon that arises in the current digital era is sourced from the theory of diffusion-innovation. This theory explains that communicators or messengers who get information from mass media will have the power to influence people around them. Thus, innovations or discoveries obtained from mass media or social media will be disseminated again across mass media or social media. The diffusion-innovation theory has a role as an agent of change in mass media or social media. This theory explains that something new will make people interested and make people want to spread it to other people.

The contemporary media environment has important implications on how scientists monitor scientific developments and communicate their research. For example, American neurologists now rely on a variety of cross-media channels, including traditional journalistic outlets (e.g. newspapers, magazines, radio, and television), new media such as blogs, and interpersonal social networks to keep up with new developments in research. In addition, the traditional form scientists use to reach the public includes interacting with journalists who cover their research in the mass media, to be further disseminated through Web 2.0 tools. Therefore, in addition to traditional communication efforts undertaken by researchers, the use of several online channels can heighten the impact of other forms of outreach. On the other hand, there exists the "saganisation" effect. Some researchers might argue that scientists who are too often involved on social media will suppress the impact of other forms of outreach (e.g. interaction with journalists). Researchers have not provided empirical evidence that interactions between various forms of outreach exist. If the work of scientists is tweeted by leading science journalists like Andrew Revkin, who has more than 50,000 followers on Twitter, by scientists like Neil deGrasse Tyson with more than 1.5 million followers on Twitter, or science media outlets like Science Friday with more than 446,000 followers on Twitter, that said work is likely to attract more attention and have a greater impact even in academia, compared to studies that are only published in academic outlets reviewed by peers - even elite outlets such as Nature. Appreciation for public communication efforts on social media can ultimately force academics to think more carefully about mapping academic impact on public online sites such as Google Scholar and ResearchGate.com, which combine social media metrics with scientific productivity indicators to measure wider impacts of academic's performances. Indeed, some scholars have recently called for social media to be used to complement traditional approaches to measure academic impact [13]

\section{RESEARCH METHOD}

This research is a qualitative documentation study on a number of literatures that support an analytical approach, which include studies on digital era regulations, word-ofmouth, ways of communicating in the digital era, buzzers and blogs. These studies are sourced from reference books, published scientific journals, as well as references on websites accessed through the internet.

\section{RESUlT AND DISCUSSION}

Based on the statements expressed in the introduction, the world has now entered the digital era of industry, where all aspects of life have been digitized and changed human habits, including how people communicate and conduct buying and selling transactions. Nowadays, most people prefer to shop online rather than offline. In response to this, many platforms have emerged to provide the selling of products online. At the same time, many e-commerce sites-special platforms provided for sellers and buyers to meet and make transactions online, are popping up. A person only needs to use their cell phone to surf the internet and find the item they want, and then make a transaction for said item. They then just have to wait for the item to be sent to the address they want. But a problem arises regarding the trust of customers to the seller, such as whether the goods will match with what is shown in the photo on the internet, or whether the benefits of the product are in accordance with the online description. Because customers cannot see or touch the product directly, they tend to look for reviews of a product that are written from the experience of previous customers who have bought and felt the benefits of the product. This can be turned into a good marketing strategy for the product, as people tend to trust the judgement of real buyers compared to messages conveyed through advertisements about the product. In addition, online businesses also utilize buzzers to raise their voice on the internet. Buzzers will post information about the product on social media, on a massive scale and on a regular basis. The public will then be exposed to information about the product repeatedly. After getting more and more exposed to the product, a sense of curiosity will arise and eventually turn into interest to try the product. Sharing on social media about the product will then happen again after the product is bought by the new customer.

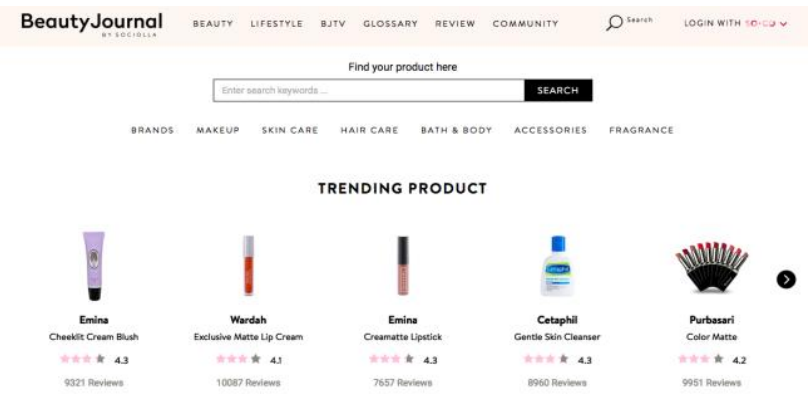

Fig. 1. Beauty Journal / SOCO by Sociolla Web Page Source: https://review.soco.id

The mix of word-of-mouth and buzzers is often done as a communication strategy for online sales. One of the implementers of this strategy is the beauty products specialist e-commerce site, Sociolla. Sociolla (PT Social Bella Indonesia) is the first e-commerce in Indonesia that specializes in selling beauty products, established in 2015. Up 
until now, Sociolla still focuses on generating sales through online websites and mobile apps, although occasionally they would open booths at beauty bazaars and other beauty events. Besides actively operating on their website, Sociolla also runs active accounts on various social media platforms such as LINE, Facebook, Twitter, Instagram, Tumblr, Youtube, and Pinterest. In addition to selling beauty products, Sociolla also provides a variety of websites and platforms related to beauty topics, such as SOCO (Sociolla Community - a community for beauty enthusiasts), Beauty Journal (for blogs and lifestyle content), and Beautylink. Sociolla has also worked closely with many beauty influencers, such as Jovi Adhiguna, Tasya Farasya, Lizzie Parra, and other known names. This form of collaboration is usually done through sending products to the KOL, coupled with endorsements when a big promo is launched.

\section{RECENTLY REVIEWED}

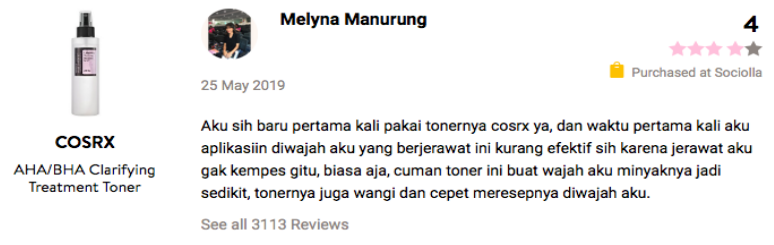

Fig. 2. Product Review on the SOCO Page Source: https://review.soco.id

Sociolla owns SOCO, which is a User Generated Content (UGC) platform to integrate Sociolla and Beauty Journal, created to ensure consumers get a more optimal, relevant and personalized experience. To put it simply, SOCO is known as a community or forum where consumers can share reviews as well as the latest information about new products. Consumers are also allowed to upload articles, videos, tips, and other types of content related to beauty and lifestyle, especially for women. This forum sets apart Sociolla from other ecommerce sites as their competitors. On top of that, Sociolla is also able to monitor various products sold, product requests from consumers, and more insights regarding feedback from the consumers to the company. Sociolla often collaborates with beauty influencers or buzzers on social media to increase consumer knowledge of Sociolla. This strategy proves to be effective because, as reported from id.techinasia.com, access to Sociolla's website jumped to 4.8 million in Q1 of 2019, which is an increase of $236 \%$ compared to what they achieved in Q1 of 2018 where they only gathered 1.4 million visitors. In just a span of one year, Sociolla has made it into the top 10 in Indonesia's e-commerce map based on data retrieved from iPrice.

\section{CONCLUSION}

Digital has become ubiquitous and inevitable. Every day, fewer non-digits are left, as more people are becoming digital immigrants and eventually, they will be replaced by digital natives. Billions of devices are now connected due to remote access and added value of IoT that have now become the norm. The Cloud Service has replaced previous digital products, making personal data more valuable than most other resources. Today, it's almost impossible for anyone to exist outside of Digital. This, too, affects the activity of buying and selling. Trading activities can now be done anytime, anywhere, and with anyone, even with people who are thousands of kilometers apart thanks to the internet. But this phenomenon also comes with a few problems, because buyers cannot see the products directly and can only rely on photos or comments from previous consumers. These consumer comments can be a benchmark of trust for other potential customers; the more positive comments given by previous consumers, the more confident prospective consumers will be in terms of buying the product. In addition to word-of-mouth, buzzers can increase the general public's trust by increasing their product knowledge as many people talk about the product constantly. Both of these ways of marketing have become promising communication strategies that are now used by various companies to market their products.

\section{REFERENCES}

[1] Behringer. W, Communications Revolutions: A historiographical concept, German History, 24(3), 333-374. https://doi.org/10.1191/0266355406gh378oa, 2006.

[2] Munar. A.M \& Jacobsen. J.K.S, "Motivations for sharing tourism experiences through social media", Tourism Management, Vol. 43, pp. 46-54, 2013.

[3] Bronner. Fred and R. de Hoog, "Vacationers and eWOM: Who Posts, and Why, Where, and What?. Journal of Travel Research", Vol 50(1), halaman 15-26. 2011

[4] Ring. A, Tkaczynski. A, \& Dolnicar. S, Word-of-Mouth Segments, Journal of Travel Research, 55(4), 481-492. https://doi.org/10.1177/0047287514563165, 2014.

[5] Katz. E and Lazarsfeld. P F, Personal Influence. Glencoe, IL: The Free Press, 1995.

[6] Beal. G. M, and Rogers. E.M, "Informational Success In The Adoption Process Of New Fabrics" Journal of Home Economics XLIX, pp. 63034, 1957.

[7] Roselius. T, 'Consumer Rankings of Risk Reduction Methods', Journal of Marketing, Vol. 35 No.1, p56-61, 1971.

[8] Hart. WL, Heskett. J L and Sasser W E Jnr, The Profitable Art of Service Recovery', Harvard Business Review, July-August pp 148-56, 1990.

[9] Gremler. DD and Brown. S W, Service Loyalty: Its nature Importance and Limitations in Edvardsson, B, Brown, S W, Johnson, R and Scheuing, E (eds) QUIS V Advancing Service Quality: A Global Perspective ISQA New York, pp171-181, 1996.

[10] Reichheld. F. F \& Sasser. W. E, Zero defections: quality comes to services, Harvard Business Review, 1990.

[11] Rafiee, M., \& Ackall, P. J. B. L, O u r n a 1, 78(3), 172-174, 2000

[12] Veil, S. R., Reno, J., Freihaut, R., \& Oldham, J, Online activists vs. Kraft foods: A case of social media hijacking, Public Relations Review, 41(1), 103-108. https:// doi.org/10.1016/j.pubrev.2014.11.017, 2014.

[13] Corley, E. A., Yeo, S. K., Xenos, M., Su, L. Y.-F., Nealey, P., Liang, X., Brossard, D, Building Buzz. Journalism \& Mass Communication Quarterly, 91(4), 772-791, 2014. 